\title{
Management of Glaucoma Capsulare: Outcomes and Complications of Trabeculectomy
}

\author{
Abdul Rafio Soomro ${ }^{1}$, Fayaz Ahmed Soomro², Munawar Hussain ${ }^{3}$, Abdul Qadeem Soomro ${ }^{4}$ \\ Asif Mashood Qazi ${ }^{5}$, Anas Bin Tariq ${ }^{6}$ \\ ${ }^{1-5}$ Al-Ibrahin Eye Hospital, Isra Postgraduate institute of Ophthalmology, ${ }^{6}$ Al-Tibri Medical College \& Hospital Isra \\ University, Karachi Campus
}

\begin{abstract}
Purpose: To analyze the results of filtration surgery in cases of Glaucoma Capsulare.

Study Design: Interventional case series.

Place and Duration: Al-Ibrahim Eye Hospital, Karachi, from January 2018 to December 2018.

Methods: Forty eyes of forty patients, between 50 to 80 years of age, with Glaucoma Capsulare, not controlled with topical medication were included in the study. Patients not willing for filtration surgery and those who had any other ocular disease were excluded. Pre-operative examination, including visual acuity, retinoscopy, intra ocular pressure and fundus examination was done. Complete blood count, blood sugar and urine complete were also carried out to rule out any other illness. All collected data was analyzed through software SPSS version 20.
\end{abstract}

Results: There were 26 (65.0\%) males and 14 (35.0\%) females. Mean age was $62.1 \pm 12.44$ years. Mean preoperative IOP was $34.0 \pm 2.43 \mathrm{~mm} \mathrm{Hg}$. At first follow-up visit mean IOP $(\mathrm{mm} \mathrm{Hg})$ was $11.44 \pm 3.2$ and at 12 weeks follow-up, the IOP was $10.14 \pm 4.1$. Angle 0 - I (closed angle) was seen in $6(15.0 \%)$, Angle grade II - III (Open angle) was seen in $10(25.0 \%)$ and grade III - IV (open angle) was seen in $24(60.0 \%)$ patients. Base line visual acuity was 6/9 in 4 (10.0\%), 6/12 - 6/18 in 10 (25.0\%), 6/18 - 6/24 in 12 (30.0\%) and 6/36 - 6/60 in 14 $(35.0 \%)$ patients. Early complications were flat anterior chamber in $4(10 \%)$ and corneal edema in $4(10 \%)$ patients. However late complications were hyphema and cataract in $2(5 \%)$ and $25(62.5 \%)$ patients respectively.

Conclusion: Trabeculectomy significantly lowers the intraocular pressure in patients with Glaucoma Capsulare.

Key Words: Glaucoma Capsulare, Trabeculectomy, Gonioscopy, Hyphema, Pseudoexfoliation glaucoma.

How to Cite this Article: Soomro AR, Soomro FA, Hussain M, Soomro AQ, Qazi AM, Tariq AB. Management of Glaucoma Capsulare: Outcomes and Complications of Trabeculectomy. Pak J Ophthalmol. 2020; 36 (4): 355359.

Doi: https://doi.org/10.36351/pjo.v36i4.1000

\section{INTRODUCTION}

Glaucoma is one of the leading causes of irreversible blindness. Pseudo-exfoliation glaucoma (PXG)/ Glaucoma Capsulare is the most common secondary

Correspondence: Anas Bin Tariq

Al-Tibri Medical College \& Hospital Isra University, Karachi Campus

Email: anastariq93@gmail.com

Received: February 7, 2020

Accepted: July 29, 2020 open-angle glaucoma, which occurs in elderly population. ${ }^{1}$

Five to six million people are affected with PXG globally. In a report of WHO, it has been notified that glaucoma accounts for 15 percent of total global blindness (43 percent after cataract). ${ }^{2}$ In Pakistan the prevalence of Glaucoma Capsulare is $6.45 \%$. $^{3}$

Many people of East Asia, due to shallower anterior chamber depth are prone to develop angle closure glaucoma. ${ }^{4}$ Initially, optic nerve head and visual fields are normal regardless of the measurement 
of intraocular pressure (IOP). In comparison, patients with PXG, have elevated IOP with glaucomatous damage to the optic nerve head along with the pseudoexfoliation. $^{5}$ In 1954, Georgiana DvorakTheobald, pathologist and ophthalmologist, named this abnormal condition as "Pseudo-exfoliation syndrome" by finding deposits of pseudo-exfoliation material on the ciliary body, zonules and lens capsules. ${ }^{6}$ Glaucoma is classified into primary and secondary. ${ }^{7}$ Amongst the main pathophysiological features of PXG are elastosis, i.e. a disturbance of elastin metabolism and abnormal synthesis and degradation of components of the extracellular material. ${ }^{8}$ Several studies suggested that males are three times more prone than females and the disease itself is not restricted to middle-aged and elderly people only., ${ }^{9,10}$

Pseudo-exfoliation glaucoma is a clinical diagnosis. Most patients are asymptomatic and diagnosis is incidental. It is not unusual for PXG patients to present in one eye with advanced disease, in which case they may be conscious of a gradual reduction in vision. Rarely, there is a sudden increase in IOP that can cause eye pain, blurring of vision, and seeing haloes. ${ }^{11}$

Assessment of glaucoma should include tonometry, anterior chamber angle examination, Gonioscopy and Fundoscopy to look for any visible damage to optic nerve. Visual field test should also be carried out. Imaging techniques such as optical coherence tomography, laser polarimetry scanning and/or laser ophthalmoscopy scanning (Heidelberg retinal tomogram) can be used to assess the retinal nerve fiber layer. ${ }^{12,13}$

Trabeculectomy is considered as a useful procedure for the management of Glaucoma Capsulare. The purpose of this study was to observe the reduction of intraocular pressure (IOP) after trabeculectomy in cases of glaucoma capsulare.

\section{METHODS}

This was an interventional case series conducted at AlIbrahim Eye Hospital, Postgraduate Institute Malir, Karachi, from January 2018 to December 2018. Approval from ethical review committee was taken. Patients were selected using convenient sampling technique. Total forty eyes of forty patients were enrolled in this study with age ranging from fifty to eighty years. All patients with PXG not controlled with medication were included in the study. Patients with PXG, not willing for filtration surgery; those who had undergone previous filtration surgery and those with complications like cataract, corneal opacity or any other ocular pathology were excluded from the study.

Pre-operative examination included unaided visual acuity for distance and near, best spectacle- corrected visual acuity, tonometry, Gonioscopy, anterior segment examination and fundus examination. Other investigations like blood pressure, blood glucose, urine complete and blood complete were also carried out to rule out chronic illness or foci of infection in the body. Written consent was taken from each patient regarding the surgical procedure and complications. All the surgeries were conducted under local anesthesia by administration of $2 \%$ lidocaine in the retrobulbar space. The surgeon dissected fornix-based conjunctival flap and created one half-thickness scleral flap at corneo-scleral junction. During trabeculectomy, peripheral iridectomy was performed and a block of trabecular meshwork tissue was removed at the edge of corneo-scleral bed. Using monofilament 10/0 nylon sutures (around $6-7$ ), scleral flap was sutured which was adjusted for ensuring small amounts of leakage to be observed around margins of scleral flap without causing any shallowing of anterior chamber.

Post-operatively after 24 hours, the dressing was removed followed by several tests including distance visual acuity with and without pinhole and near vision. Slit lamp examination was done to assess the condition of the wound and bleb formation, anterior chamber, for depth, cells, flare and hyphema, iris for any damage, pupillary reaction, patency of peripheral iridectomy and membrane formation. Intra ocular pressure was noted by Goldman Applanation tonometer while visual acuity was measured unaided and with glasses. All patients were followed up postoperatively after one week, third week, sixth week and twelfth week during the entire study period.

Pre-operatively, visual acuity was categorized from $6 / 9$ to $6 / 60$ and IOP was categorized into 3 groups including; $28-30 \mathrm{~mm} \mathrm{Hg}, 36-38 \mathrm{~mm} \mathrm{Hg}$ and $40-42 \mathrm{~mm} \mathrm{Hg}$. Data analysis was done using SPSSS version 20 .

\section{RESULTS}

A total of 40 eyes of 40 patients were included in the study. There were $26(65.0 \%)$ males and $14(35.0 \%)$ females. Mean age of the patients was $62.1 \pm 12.44$ 
years. Mean pre-operative IOP $(\mathrm{mm} \mathrm{Hg})$ was $34.0 \pm$ $.2 .43 \mathrm{~mm} \mathrm{Hg}$. Range of IOP was $28-30 \mathrm{~mm} \mathrm{Hg}$ in 20 (50.0\%), $36-38 \mathrm{~mm} \mathrm{Hg}$ in 10 (25.0\%) and $40-42$ $\mathrm{mm} \mathrm{Hg}$ in $10(25.0 \%)$ patients. Grade 0 - I (Closed Angle) was seen in $6(15.0 \%)$ patients, grade II - III (Open Angle) in $10(25.0 \%)$ and angle grade III - IV (Open Angle) in $24(60.0 \%)$ patients. Visual acuity was $6 / 9$ in $4(10.0 \%), 6 / 12-6 / 18$ in $10(25.0 \%), 6 / 18$ $-6 / 24$ in $12(30.0 \%)$ and $6 / 36-6 / 60$ in $14(35.0 \%)$ patients (Table 1). For further details, see table 2.

Table 1: Showing Intraocular Pressure Range and Visual Acuity at Baseline.

\begin{tabular}{llc}
\hline Variable & \multicolumn{1}{c}{ Range } & Mean \pm SD n (\%) \\
\hline \multirow{3}{*}{ IOP } & $28-30 \mathrm{mmHg}$ & $20(50.0 \%)$ \\
& $36-38 \mathrm{mmHg}$ & $10(25.0 \%)$ \\
Grading of the & I -0 (Closed Angle) & $10(25.0 \%)$ \\
Angle & II - III (Open Angle) & $6(15.0 \%)$ \\
& III - IV (Open Angle) & $24(25.0 \%)$ \\
& $6 / 9$ & $4(10.0 \%)$ \\
Visual Acuity & $6 / 12-6 / 18$ & $10(25.0 \%)$ \\
& $6 / 18-6 / 24$ & $12(30.0 \%)$ \\
& $6 / 36-6 / 60$ & $14(35.0 \%)$ \\
\hline
\end{tabular}

Table 2: Showing Intraocular Pressure Ranges and Visual Acuity at $1^{\text {st }}$ And $12^{\text {th }}$ Week of Treatment.

\begin{tabular}{llcr}
\hline Follow-up & Variable & Range & $\begin{array}{c}\text { Mean } \mathbf{E D} \\
\mathbf{n}(\boldsymbol{\%})\end{array}$ \\
\hline & Range of & $4-8 \mathrm{~mm} \mathrm{Hg}$ & $8(20.0 \%)$ \\
& IOP & $10-14 \mathrm{~mm} \mathrm{Hg}$ & $20(50.0 \%)$ \\
At First & & $6 / 9$ & $12(30.0 \%)$ \\
Week & Visual & $6 / 12-6 / 18$ & $4(10.0 \%)$ \\
& Acuity & $6 / 18-6 / 24$ & $8(20.0 \%)$ \\
& & $6 / 36-6 / 60$ & $20(50.0 \%)$ \\
& Range of & $4-8 \mathrm{~mm} \mathrm{Hg}$ & $26(65.0 \%)$ \\
& IOP & $10-12 \mathrm{~mm} \mathrm{Hg}$ & $10(25.0 \%)$ \\
At Twelve & & $14-16 \mathrm{~mm} \mathrm{Hg}$ & $4(10.0 \%)$ \\
Week & & $6 / 12-6 / 18$ & $9(22.5 \%)$ \\
& Visual & $6 / 18-6 / 24$ & $6(15.0 \%)$ \\
& Acuity & $6 / 36-6 / 60$ & $22(55.0 \%)$ \\
& & $\mathrm{H} . \mathrm{M}-\mathrm{PL}+\mathrm{ve}$ & $3(7.5 \%)$ \\
\hline
\end{tabular}

$\mathrm{IOP}=$ Intraoccular pressure

$\mathrm{PL}=$ Perception of light

$\mathrm{HM}=$ hand movement

Early complications were flat anterior chamber in $4(10 \%)$ and corneal edema in $4(10 \%)$ patients. However late complications were hyphema and cataract in $2(5 \%)$ and $25(62.5 \%)$ patients respectively.

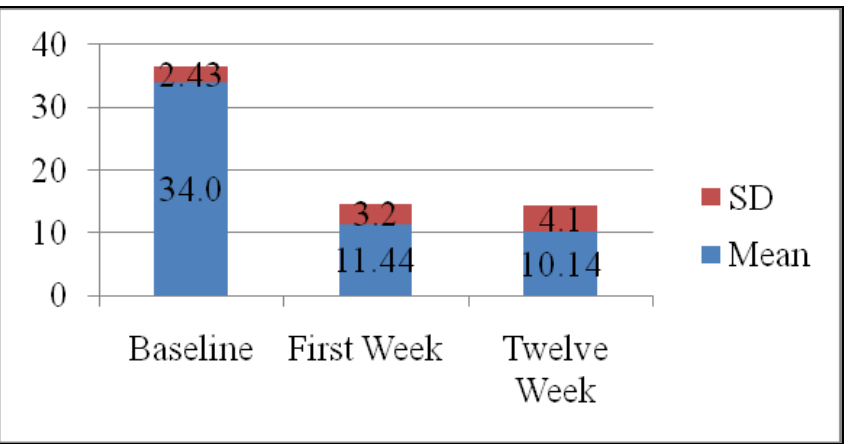

Fig. 1: Showing Intraocular Pressure $(\mathrm{mm} \mathrm{Hg})$ Before and After Treatment.

\section{DISCUSSION}

Association of pseudo-exfoliation to increased IOP has been well documented and proposed that patients with bilateral pseudo-exfoliation, are usually older and have higher prevalence of glaucoma or ocular hypertension in comparison to patients with unilateral involvement. ${ }^{14,15}$ Genetic factors are also linked as a predisposing factor, however the results are still not clear and studies are still on-going in this respect. ${ }^{16} \mathrm{In}$ our study, patients had either unilateral or bilateral disease.

In a study 37 patients with mean age of $62.1 \pm$ 10.4 years were analyzed. Mean baseline IOP was $18.16 \pm 5.91 \mathrm{~mm} \mathrm{Hg}$. They underwent trabeculectomy and the IOP at final follow up decreased significantly to $15.37 \pm 2.90 \mathrm{mmHg} .{ }^{17}$ Similarly, in our study the baseline IOP was $34.0 \pm 2.34 \mathrm{~mm} \mathrm{Hg}$ which decreased significantly to $11.44 \pm 3.2 \mathrm{~mm} \mathrm{Hg}$ at $1^{\text {st }}$ week and to $10.14 \pm 4.1 \mathrm{~mm} \mathrm{Hg}$ at the final follow-up at $12^{\text {th }}$ week of treatment.

In Normal Tension Glaucoma (NTG), glaucoma filtration surgery has been well-documented. ${ }^{18}$ Aoyama reported that visual field progression among NTG patients was arrested in majority of patients after filtration surgery. ${ }^{19}$ In our study, significant decrease in IOP was observed post-operatively.

Jampel et al. reported hypotony in $15-20 \%$ patients undergoing trabeculectomy with antineoplastic agents. ${ }^{20}$ There are also reports which show that hypotony did not have any effect on visual acuity. ${ }^{21}$ Similarly, Goodkin et al observed that eyes with post-operative hypotony and absence of foveal disruption often retained good central visual acuity. ${ }^{22}$ However, hypotony was not reported as a postoperative complication in our study. Flat or shallow anterior chamber, corneal edema and hyphema were 
the post-operative complication found in 04, 04 and 02 patients.

Another study by Hirooka et $\mathrm{al}^{23}$ determined to evaluate the vision-related quality of life following glaucoma filtration surgery on 103 glaucoma patients, the baseline IOP was $19.0 \pm 8.1 \mathrm{~mm} \mathrm{Hg}$ while the post-operative IOP was $9.7 \pm 3.9 \mathrm{~mm} \mathrm{Hg}$ showing a significant decrease in IOP $(\mathrm{p}<0.001)$. The study also reported that glaucoma filtration surgery in combination with cataract filtration surgery was found to have higher significant improvement in visionrelated quality of life. Although in our study, similar significant decrease in IOP from $34.0 \pm 2.34 \mathrm{~mm} \mathrm{Hg}$ at baseline to $10.14 \pm 4.1$ and $\mathrm{mm} \mathrm{Hg}$ at the final follow up at $12^{\text {th }}$ week was observed.

Francis et al in a study on 23 patients of glaucoma undergoing trabeculectomy reported a baseline IOP of $23.0 \pm 10.7 \mathrm{~mm} \mathrm{Hg}$ and post-operative IOP of $11 / 0 \pm$ $5.7 \mathrm{~mm} \mathrm{Hg} .{ }^{24}$ However, significant complications were also reported such as hypotony and choroidal detachment. Similarly, Rao et al in a study on 72 patients with baseline IOP of $20.3 \pm 7.2 \mathrm{~mm} \mathrm{Hg}$ and post-operative IOP of $15.5 \pm 3.5 \mathrm{~mm} \mathrm{Hg}$ also reported significant post-operative complications of posterior capsular retraction, bleb leakage and endophthalmitis. ${ }^{25}$ Difference in study design, genetic variation among countries and surgical technique might play a role in different findings of results in our study as compared with the above mentioned researches.

The limitations of our study are small sample size and single-centred study. Further multi-centred studies should be considered for comparing the different treatment options of glaucoma in terms of IOP and post-operative complications.

\section{CONCLUSION}

Glaucoma filtration surgery in patients of glaucoma capsulare is safe and it significantly lowers the intraocular pressure between baseline and at subsequent post-operative follow-ups.

\section{Ethical Approval}

The study was approved by the Institutional review board/Ethical review board.

\section{Conflict of Interest}

Authors declared no conflict of interest.

\section{REFERENCES}

1. Wani FR, Romana M, Singh T, Wani IR, Wani IR, Lone RA. Prevalence of Exfoliative Glaucoma among Kashmiri Population: A Hospital Based Study. Int J Health Sci. 2009; 3 (1): 51.

2. Quigley HA, Broman AT. The number of people with glaucoma worldwide in 2010 and $2020 . \mathrm{Br} \mathrm{J}$ Ophthalmol. 2006; 90 (3): 262-267.

3. Rao RQ, Arain TM, Ahad MA. The prevalence of Pseudo-exfoliation syndrome in Pakistan. Hospital based study. BMC Ophthalmology, 2006 Dec; 6 (1): 15.

4. Wang N, Wu H, Fan Z. Primary angle closure glaucoma in Chinese and Western populations. Chin Med J. 2002; 115 (11): 1706-1715.

5. Zenkel M, Krysta A, Pasutto F, Juenemann A, Kruse FE, Schlötzer-Schrehardt U. Regulation of lysyl oxidase-like 1 (LOXL1) and elastin-related genes by pathogenic factors associated with pseudoexfoliation syndrome. Invest Ophthalmol Vis Scie. 2011; 52 (11): 8488-8495.

6. Dvorak-Theobald G. Pseudo-exfoliation of the lens capsule*: relation to "true" exfoliation of the lens capsule as reported in the literature and role in the production of glaucoma capsulocuticulare. Am J Ophthalmol. 1954; 37 (1): 1-2.

7. Chen Y, Lin Y, Vithana EN, Jia L, Zuo X, Wong TY, et al. Common variants near ABCA1 and in PMM2 are associated with primary open-angle glaucoma. Nature genetics, 2014; 46 (10): 1115.

8. Ritch R, Schlötzer-Schrehardt U. Exfoliation syndrome. Surv Ophthalmol. 2001; 45 (4): 265-315.

9. Zenkel M, Krysta A, Pasutto F, Juenemann A, Kruse FE, Schlötzer-Schrehardt U. Regulation of lysyl oxidase-like 1 (LOXL1) and elastin-related genes by pathogenic factors associated with pseudoexfoliation syndrome. Invest Ophthalmol Vis Sci. 2011; 52 (11): 8488-8495.

10. Taqi U, Fasih U, Jafri SF, Sheikh A. Frequency of primary open angle glaucoma from Abbasi Shaheed Hospital. J Pak Med Assoc. 2011; 61 (8): 778.

11. Stamper RL, Lieberman MF, Drake MV. BeckerShaffer's Diagnosis and Therapy of the Glaucomas EBook. Elsevier Health Sciences; 2009

12. Farandos NM, Yetisen AK, Monteiro MJ, Lowe CR, Yun SH. Contact lens sensors in ocular diagnostics. Adv Healthcare Mat. 2015; 4 (6): 792-810.

13. Lim TC, Chattopadhyay S, Acharya UR. A survey and comparative study on the instruments for glaucoma detection. Med Eng Phys. 2012; 34 (2): 129-139.

14. Plateroti P, Plateroti AM, Abdolrahimzadeh S, Scuderi G. Pseudoexfoliation syndrome and pseudoexfoliation glaucoma: a review of the literature with updates on surgical management. J Ophthalmol. 2015; 2015: 370371. Doi:10.1155/2015/370371. 
15. Mansoor HM, Fawzi HA. Clinical Survey of Pseudoexfoliation Syndrome. Glob J Health Sci. 2019; 11 (5): 144-148.

16. Moghimi S, Latifi G, Amini H, Mohammadi M, Fakhraie G, Eslami Y, et al. Cataract surgery in eyes with filtered primary angle closure glaucoma. J Ophth Vis Res. 2013; 8 (1): 32-38.

17. Kim CS, Seong GJ, Lee NH, Song KC, Society KG. Namil Study Group. Prevalence of primary open-angle glaucoma in central South Korea: the Namil study. Ophthalmology, 2011; 118 (6): 1024-1030.

18. Tham YC, Li X, Wong TY, Quigley HA, Aung T, Cheng CY. Global prevalence of glaucoma and projections of glaucoma burden through 2040: a systematic review and meta-analysis. Ophthalmology, 2014; 121 (11): 2081-2090.

19. Aoyama A, Ishida K, Sawada A, Yamamoto T. Target intraocular pressure for stability of visual field loss progression in normal-tension glaucoma. Jap $\mathbf{J}$ Ophthalmol. 2010; 54 (2): 117-123.

20. Jampel HD, Solus JF, Tracey PA, Gilbert DL, Loyd TL, Jefferys JL, et al. Outcomes and bleb-related complications of trabeculectomy. Ophthalmology, 2012; 119 (4): 712-722.

21. Schultz SK, Iverson SM, Shi W, Greenfield DS. Achieving Single-Digit Intraocular Pressure Targets with Filtration Surgery in Eyes with Progressive Normal-Tension Glaucoma. J Glaucoma, 2016; 25 (2): 217.

22. Goodkin ML, Grewal DS, Greenfield DS. Threedimensional high-speed optical coherence tomography for diagnosis of hypotony maculopathy after glaucoma filtration surgery. J Glaucoma, 2010; 19 (6): 349-355. Doi: 10.1097/IJG.0b013e3181bd59c.
23. Hirooka K, Nitta E, Ukegawa K. Vision-related quality of life following glaucoma filtration surgery. BMC Ophthalmol. 2017; 17: 66. https://doi.org/10.1186/s12886-017-0466-7

24. Francis BA, Winarko J. Combined Trabectome and cataract surgery versus combined trabeculectomy and cataract surgery in open-angle glaucoma. Clin Surg Ophthalmol. 2011; 29: 4-10.

25. Rao HL, Maheshwari R, Senthil S, Prasad KK, Garudadri CS. Phacotrabeculectomy without mitomycin $\mathrm{C}$ in primary angle-closure and open-angle glaucoma. J Glaucoma, 2011; 20 (1): 57-62.

\section{Authors' Designation and Contribution

Abdul Rafio Soomro; Consultant Ophthalmologist: Concept, design \& write up of study.}

Fayaz Ahmed Soomro; Senior Consultant Ophthalmologist: Concept, design \& final approval of study.

Munawar Hussain; Assistant Professor: Concept, design \& corrections of the study.

Abdul Qadeem Soomro; Associate Professor: Concept \& design of study.

Asif Mashood Qazi; Associate Professor: Concept \& final approval of study.

Anas Bin Tariq; Lecturer: Data collection, data analysis \& write-up. 